\title{
Worries and concerns of Inflammatory Bowel Disease (IBD) patients in Belgium - a validation of the Dutch Rating Form
}

\section{Short title: Dutch Rating Form of IBD Patient Concerns}

Marta Walentynowicz ${ }^{\mathrm{a}, \mathrm{b}}$, Iris Van de Pavert ${ }^{\mathrm{c}}$, Sofie Coenen ${ }^{\mathrm{d}, \mathrm{e}}$, Liselotte Fierens ${ }^{\mathrm{e}}$, Johan Vlaeyenc, Andreas von Leupoldtc ${ }^{c}$, Lukas Van Oudenhove ${ }^{\mathrm{e}, \mathrm{f}}$, Séverine Vermeire ${ }^{\mathrm{d}, \mathrm{e}}$, Gert Van Assche $^{\mathrm{d}, \mathrm{e}}$, Marc Ferrante ${ }^{\mathrm{d}, \mathrm{e}}$, Ilse Van Diest ${ }^{\mathrm{c}}$

${ }^{a}$ Centre for the Psychology of Learning and Experimental Psychopathology, KU Leuven, Leuven, Belgium

${ }^{b}$ Psychological Science Research Institute, Université catholique de Louvain, Louvain-laNeuve, Belgium

${ }^{c}$ Health Psychology Research Group, KU Leuven, Leuven, Belgium

${ }^{d}$ Department of Gastroenterology and Hepatology, University Hospitals Leuven, KU Leuven, Leuven, Belgium

e Translational Research Center for Gastrointestinal Disorders (TARGID), Department of Clinical and Experimental Medicine, KU Leuven, Leuven, Belgium

${ }^{f}$ Cognitive and Affective Neuroscience Lab, Department of Psychological and Brain Sciences, Dartmouth College, Hanover, NH, USA

Journal: Scandinavian Journal of Gastroenterology

DOI: 10.1080/00365521.2020.1839962

\section{Degrees of all authors \& contact details for all authors}

Marta Walentynowicz,PhD; marta.walentynowicz@kuleuven.be

Iris Van de Pavert, MSc; iris.vandepavert@kuleuven.be

Sofie Coenen, MSc; sofie.coenen@uzleuven.be

Liselotte Fierens, MSc; liselotte.fierens@kuleuven.be

Johan Vlaeyen, PhD johannes.vlaeyen@kuleuven.be

Andreas von Leupoldt, PhD; andreas.vonleupoldt@kuleuven.be

Lukas Van Oudenhove, MD PhD; lukas.vanoudenhove@kuleuven.be

Séverine Vermeire, MD PhD; severine.vermeire@uzleuven.be 
Gert Van Assche, MD PhD; gert.vanassche@uzleuven.be

Marc Ferrante, MD PhD; marc.ferrante@uzleuven.be

Ilse Van Diest, PhD; Ilse.VanDiest@kuleuven.be

\section{Address for correspondence}

Ilse Van Diest, PhD

Health Psychology

KU Leuven

Tiensestraat 102 - box 3726

3000 Leuven

Belgium

Tel: +3216326029

ilse.vandiest@kuleuven.be

\section{Funding details}

This work was supported by the "Asthenes" long-term Methusalem structural funding from the Flemisch Government under Grant METH/15/011; Research Foundation Flanders under Grant G071918N.

S Vermeire and M Ferrante are Senior Clinical Investigators of the Research Foundation Flanders (FWO), Belgium.

L Van Oudenhove is an associate research professor of the KU Leuven Special Research Fund.

\section{Disclosure statement}

M Ferrante reports financial support for research: Amgen, Biogen, Janssen, Pfizer, Takeda; Consultancy: Abbvie, Boehringer-Ingelheim, Celltrion, Ferring, Janssen, Lilly, MSD, Pfizer, Sandoz, Takeda and Thermo Fisher; Speakers fee: Abbvie, Amgen, Biogen, BoehringerIngelheim, Chiesi, Falk, Ferring, Janssen, LameproMSD, Mylan, Pfizer, Sandoz, Takeda, and Truvion Healthcare. L Van Oudenhove reports financial support for research from Nestlé and consultancy for Danone. G Van Assche received honoraria and/or research support from: Abbvie, MSD, Ferring, Janssen, Roche, Takeda and Pfizer. 
Word count (main body): 2967

Abbreviations

BIC: Bayesian Information Criterion ; CD: Crohn's disease; CE: correlated errors; CFA:

confirmatory factor analyses; CFI: comparative fit index; Cl: confidence interval; DASS-21:

Depression Anxiety Stress Scale; df: degrees of freedom; IBD: Inflammatory Bowel Disease;

RFIPC: Rating Form of Inflammatory Bowel Disease Patient Concerns; RMSEA: root mean

square error of approximation; SD: standard deviation; UC: ulcerative colitis 


\section{Abstract}

Objectives: Worry is the most common psychological complaint among patients with Inflammatory Bowel Disease (IBD). This study aimed to translate and test the psychometric properties the Rating Form of IBD Patient Concerns (RFIPC) among Dutch-speaking patients with IBD in Belgium. It also aimed to describe worries and concerns, and to examine possible differences in worry patterns between patients with different disease types and disease activities.

Methods: The RFIPC was translated into Dutch following the guidelines of the Rome Foundation and was completed by patients with Crohn's disease $(C D, n=336)$ and ulcerative colitis (UC, $n=160)$. To test concurrent validity, the Depression Anxiety Stress Scales (DASS-21) were used. Factor structure was examined with confirmatory factor analysis.

Results: The 4-factor structure including subscales "impact of the disease", "sexual intimacy", "complications of the disease", and "body stigma" was confirmed in the Dutch sample. All factors had high internal consistency (> .70). Correlations with DASS-21 suggest good concurrent validity, all $r s>.30, p s<.001$. No differences in the RFIPC scores were observed between patients with CD and UC. Patients with active disease (53\%) had higher scores than patients in remission (47\%). Across all groups, the order of top concerns was consistent and included worries about energy level, side effects of medication, having an ostomy bag/surgery, and uncertain nature of the disease.

Conclusions: The Dutch version of the RFIPC is a valid and reliable measure of IBD-specific worries and concerns which can be used in both research and clinical settings. 
Keywords: Inflammatory bowel disease, Crohn's disease, ulcerative colitis, disease-specific concerns, worry 


\section{Introduction}

Inflammatory Bowel Diseases (IBD), including Crohn's disease (CD) and ulcerative colitis (UC), are chronic inflammatory conditions of the gastrointestinal tract characterized by sequences of flares and remission. The last decades have witnessed a significant increase in both incidence and prevalence of IBD cases, with prevalence in Europe now estimated around 800 per 100,000 persons $^{1}$. The most common symptoms among IBD patients include abdominal pain, diarrhea, rectal bleeding, and bloating, often accompanied by fatigue and weight loss. These physical complaints coincide with a range of psychological symptoms, of which worry was identified as the most burdensome ${ }^{2}$.

One of the most widely used instruments to measure IBD-specific worries and concerns in adult populations worldwide ${ }^{3}$ is the Rating Form of IBD Patient Concerns (RFIPC) ${ }^{4}$. This scale consists of 25 statements representing worries and concerns based on the complaints expressed by IBD patients during either consultation with a physician or a semi-structured interview ${ }^{4}$. Following the results of the original exploratory factor analysis, Drossman et al. ${ }^{4}$ grouped 22 of the 25 items related to worries and complaints into 4 subscales: "impact of the disease", "sexual intimacy", "complications of the disease", and "body stigma". This factor structure of the original English language version was supported (with minor adaptations) in other language versions $s^{5,6}$. However, a 6-factor structure was also suggested in the Norwegian version", which included the following factors: "impact of the disease", "expectancy", "treatment", "sexual intimacy", "complications of the disease", and "body stigma“. The RFIPC has been translated and validated in several languages ${ }^{5-9}$. Across all versions, this instrument was shown to be a reliable and valid measure of worries and concerns of patients with IBD, which can be used in both research and clinical settings. For research purposes, it has been used to identify patients' worries and concerns ${ }^{4,6}$, to 
compare them between patients with different disease types (e.g., CD vs. UC) ${ }^{4,6}$ and disease activities (e.g., active disease vs. remission) ${ }^{8}$, to track the changes in worries over time ${ }^{6-8}$, and to perform cross-cultural comparisons of disease-specific worries ${ }^{10}$. In clinical practice, it can be used by physicians and nurses to offer more personalized education and treatment by focusing on the most burdensome IBD-related worries of a specific patient.

Although the RFIPC was translated into several languages, a Dutch translation is still lacking. Dutch is the third most widely spoken Germanic language and is used by more than 22 million people, mostly in the Netherlands and in parts of Belgium. As in the rest of Europe, prevalence rates of IBD in the Netherlands are increasing ${ }^{11,12}$, and the last estimates suggest a point prevalence between 432 and 830 per 100,000 inhabitants in $2010^{11,12}$. Dutch speaking patients with IBD were also reported to have a lower quality of life than the general population ${ }^{11}$. It points to the need to design better interventions that will not only reduce the physical symptoms associated with IBD but also improve patients' quality of life. Understanding worries and concerns of IBD patients, for example through the administration of the RFIPC, could support this process.

This study aimed to translate and test the psychometric properties of the RFIPC and its factor structure among Dutch-speaking patients with CD and UC in Belgium. In addition, it aimed to assess worries and concerns in a Dutch-speaking sample and examine possible differences in worry patterns between patients with different disease types and disease activities.

\section{Methods}

Participants 
Dutch-speaking patients with an IBD diagnosis were invited to participate at the IBD infusion unit of the University Hospital Leuven, Leuven, Belgium. These patients visited the unit to receive infliximab, vedolizumab, or ustekinumab as their main treatment for IBD. Patients were elligible if they were between 18 and 85 years old, received an UC or CD diagnosis at least 3 months before the participation, had a good understanding of Dutch, and Diagnosis of UC or CD was based on clinical, radiological, and endoscopic examination and histological findings ${ }^{13}$. Exclusion criteria were the presence of comorbid disease, use of treatments other than infliximab, vedolizumab, or ustekinumab, and the presence of an ostomy or a ileal pouch-anal anastomosis. A total of 499 were willing to participate (response rate $=84$ \%). Patients in whom more than $75 \%$ of the RFIPC data were missing were excluded $(n=3)$, resulting in a final dataset of 496 patients. Participants signed the informed consent prior to participating in the study. The study was approved by the Ethics Committee of Research of the University Hospital Leuven (S61352).

Materials

The RFIPC was used as a measure of worries and concerns associated with IBD and its treatments ${ }^{4}$. This questionnaire includes 25 disease-specific concerns, which are rated on $10 \mathrm{~cm}$ visual analog scales ranging from 0 (not at all concerned) to 100 (a great deal concerned) in response to a question "Because of your condition, how concerned are you with...?". The original questionnaire was translated to Dutch following the guidelines of the Rome Foundation ${ }^{14}$. First, two independent professional Dutch translators, familiar with medical translations, translated the questionnaire from English to Dutch. The two translations were compared, and a preliminary version was selected under the supervision of a monitoring clinician appointed by the Rome Foundation. Next, this version was 
translated back into English by another professional translator. The backtranslation and the original questionnaire were compared, and a final Dutch version of the questionnaire was agreed upon by the monitoring clinician.

Depression Anxiety Stress Scales (DASS-21) was used to measure the levels of depression, anxiety, and stress experienced in the past week ${ }^{15}$. The validated Dutch version was used ${ }^{16}$. In this 21-item version, each subscale is measured with 7 items, and answers are provided on a 4-point Likert scale ranging from 0 (not at all or never applicable) to 3 (surely or most of the time applicable). Scores are doubled to make them comparable to the full 42 -item version. Cronbach's alphas in the current sample were .91 for depression, .83 for anxiety, and .92 for stress subscales.

Disease status. Whether a patient was in clinical remission or had an active disease was based on patient-reported outcome values. Participants with $C D$ were asked about their average daily stool frequency and average abdominal pain in the past week, ranging from "no fluid stools/no pain" to "10 or more/severe pain"17. Participants with UC were asked about the average daily stool frequency compared to when the disease is under control and rectal bleeding over the past three days, ranging from "normal number of stools/no blood in stool" to "at least five more stools than usual/almost pure blood in most of the stool"18. Active disease was defined as an abdominal pain score $>1$ or a liquid to very soft stool frequency $>1.5$ for $C D$ patients ${ }^{17}$ and as rectal bleeding score $>0$ or a stool frequency score $>1$ for patients with $U C^{18}$. Clinical remission was defined as an abdominal pain score $\leq 1$ and a liquid to very soft stool frequency $\leq 1.5$ for $C D$ patients ${ }^{17}$ and as rectal bleeding score $=0$ and a stool frequency score $\leq 1$ for patients with UC ${ }^{18}$. 


\section{Data analyses}

Descriptive statistics were used to describe the pattern of worries and concerns of IBD patients: in the total population, per disease type, and per disease activity. We used independent samples Student's t-tests to explore whether mean item and subscore levels differed between patients with different disease types and disease activity. In order to examine the rank-order stability in different groups, we have used the Spearman's rank correlation coefficient to correlate the averaged concerns ordered according to their importance for patients in different groups (CD vs. UC and active disease vs. remission) . $P$ values in item-level analyses were adjusted for multiple comparisons using the BenjaminiHochberg procedure ${ }^{19}$.

RFIPC factor structure. Confirmatory factor analyses (CFA) were performed on the whole sample to test 4 distinct models previously proposed to describe the factor structure of RFIPC: 1) the original 4-factor model including 22 items ${ }^{4}, 2$ ) an adapted 4-factor model including correlated error terms of two items ("having surgery" and "having an ostomy bag" ${ }^{6}, 3$ ) an adapted 4-factor model additionally including correlated error terms between "developing cancer" and "dying early" ${ }^{5}$, and 4) a 6-factor model". Small amount of missing values observed among 10 patients were accommodated using maximum likelihood parameter estimation. The model fit of these models was evaluated with descriptive fit measures, such as the root mean square error of approximation (RMSEA) and the comparative fit index (CFI). RMSEA values below .06 and CFI values higher than .90 were treated as the indices of a good model $\mathrm{fit}^{20}$. Because these models were not nested, we compared the models based on the Bayesian Information Criterion (BIC) to determine which 
model provided the best fit to the data. Smaller BIC values indicate a better-fitting model. A BIC difference of above 10 represents strong evidence for meaningful differences between the models, while above 100 represents decisive evidence ${ }^{21}$.

Questionnaire validation. The floor (percentage of patients who scored less than or equal to $5 \%$ lowest scores on the scale) and the ceiling effects (percentage of patients who scored greater than or equal to $5 \%$ highest scores on the scale) were calculated for both the total score and the subscores and interpreted following the customary threshold of $15 \%{ }^{22}$. Internal consistency was examined by calculating Cronbach's alpha coefficient. Values above .70 indicate acceptable internal consistency ${ }^{23}$. We evaluated concurrent validity by testing the association between the RFIPC and measures of emotional functioning (DASS-21) using Pearson correlation coefficient.

Relationship between RFIPC and population characteristics. The relationship between RFIPC - total score and subscores - and gender (men vs. women), relationship (no vs. yes), education (high school or less vs. university), and age (younger than 41 years vs. 41 years or older, determined through a median split on age) were investigated with t-tests. We adjusted $p$-values for multiple comparisons using the Benjamini-Hochberg procedure ${ }^{19}$. Analyses were performed using Mplus 8 for CFA (Muthén \& Muthén, 2017), STATA 15 for descriptive statistics (Stata, College Station, TX), and PROC MULTTEST in SAS 9.4 for multiple comparisons (SAS Institute, Cary, NC, USA).

\section{Results}

\section{Patient characteristics}

The final sample consisted of 496 patients $\left(\mathrm{M}_{\mathrm{age}}=41.9, \mathrm{SD}_{\mathrm{age}}=14.8,51.6 \%\right.$ women $)$. The majority of patients had higher education (52.2\%), were in a stable relationship (79.4\%), and 
were currently working (61.3\%). Regarding the disease-related characteristics, $67.7 \%$ were diagnosed with CD (32.3\% with UC), 52.8\% were classified as being in clinical remission (47.2\% in active disease), and $37.3 \%$ had a history of previous surgery related to the IBD.

\section{Description of concerns of IBD patients}

The mean scores for the 25 items of RFIPC for the total population are presented in Table 1 , together with the means and ranks per disease type and disease activity. Top five concerns were related to energy level, side effects of medication, having an ostomy bag/surgery, and uncertain nature of the disease. Patients rated those concerns at least 45 on a 0-100 scale. With regard to disease type, no differences were observed between patients with $C D$ and UC, neither for the total score, $M(S D)_{C D}=37.52(18.00), M(S D)_{U C}=37.41(19.86), t(494)=$ $0.06, p=.95$, nor for individual items (Table 1). In addition, the rank ordering of mean scores by patients with CD and UC was similar, with Spearman's rho $=.93, p<.001$. Consequently, factor analyses were performed on the total sample.

Concerning the effect of disease activity on worries and concerns, differences were observed between patients with active IBD, $M(S D)_{\text {active }}=42.54(18.75)$ and clinical remission IBD, $M(S D)_{\text {remission }}=32.97(17.29), t(494)=5.92, p<.001$. This was particularly the case for patients with $C D$, among whom those with active disease had much higher levels of worries than those in clinical remission (see Supplementary Table 1 for details). For individual concerns, only 2 did not differ between the IBD patients with active disease versus remission, namely dying early and passing the disease to others (Table 1). Nevertheless, the rank ordering of mean scores by patients with different disease activities was comparable, with Spearman's rho $=.90, p<.001$.

\section{RFIPC factor structure}


The factor structure of RFIPC was investigated with CFA testing 4 models previously described in the literature. The fit indices for these 4 models are shown in Table 2. None of the tested models reached the cut-off values ${ }^{20}$. Among the 4 models, the best model fit was observed for the model proposed by Jaghult ${ }^{5}$, which reached the cut-off value for CFI (.90) and had the lowest RMSEA from all tested models. This model has also outperformed other models based on the BIC values, differing by more than 100 from the second best model (model 2). The model with best fit includes the 4 factors proposed by Drossman et al. ." "disease impact", "sexual intimacy", "complications", and "body stigma", as well as correlated error terms between items 5 and 6 and items 16 and 17. Descriptive statistics for those factors and the total score are shown in Table 3.

\section{Questionnaire validation}

The floor and ceiling effects are presented in Table 3 . The floor effects ranged between $2 \%$ and $20 \%$, with proportions exceeding the customary cut-off of $15 \%$ for subscales Sexual Intimacy (16\%) and Body Stigma (20\%). The ceiling effects were low and did not exceed $1 \%$. Table 3 also shows the results concerning the internal consistency and concurrent validity of the total score and 4 subscales from model 3. Cronbach's alpha coefficient values for the total score and subscales were above .79. The RFIPC scores were significantly associated with conceptually related measures of emotional functioning measured with DASS- 21 . The associations were moderate to large, all $r s>.30, p s<.001$ (Table 3 ).

\section{Relationship between RFIPC and population characteristics}

Means for total scores and subscores per characteristic are shown in Supplementary Table 2. Women had higher scores in both total score and subscores compared to men (difference between 8 to 12 points on a scale of 100$)$, all $p s<.001$. No differences were observed with regard to education, relationship status, and age, all $p s>.05$. 


\section{Discussion}

The aims of this study were to translate and test the psychometric properties the Dutch version of the RFIPC and its factor structure, as well as to describe the worries and concerns among Dutch-speaking patients with IBD in Belgium. To this end, 336 patients with CD and 160 patients with UC treated with biological therapy completed the Dutch version of the RFIPC and the DASS-21, which measured emotional functioning. Our results supported the original factor structure of the English version ${ }^{4}$ and showed that the Dutch version of the RFIPC is a valid and reliable measure of disease-specific worries of patients with IBD. The average total score of the RFIPC was 37.5 , which was similar to the levels in the American sample ${ }^{4}$, but lower than in the Greek sample ${ }^{6}$. This is in line with past research showing that, within Europe, northern countries report overall lower levels of IBD-related concerns than southern countries ${ }^{10}$. Regarding the rank ordering of the worries expressed by the patients with IBD, the top five concerns reported by the patients in our sample showed resemblance to the ones reported in other samples ${ }^{10}$ and included energy level, side effects of medication, requiring an ostomy bag, requiring surgery, and the uncertain nature of the disease. Interestingly, almost the same order was observed for patients with CD and UC, as well as for patients with and without disease activity. This shows that, although the levels of worries might differ significantly between patients with active disease stage compared to the ones in remission, the differences are rather small, and the significance of worries is strikingly similar across groups with different clinical characteristics. This could indicate that education and treatment for all patients with IBD should focus on those concerns in the first place.

With regard to the factor structure, our analyses yielded some support for the original 4factor structure 4 , consisting of the factors which were interpreted as "impact of disease", 
"sexual intimacy", "complications", and "body stigma". All the factors had high internal consistency and at least moderate positive correlations with measures of depression, anxiety, and stress, supporting the construct validity of the RFIPC. Nevertheless, it should be mentioned that the model fit of this 4-factor model of RFIPC was at the lower limit of being acceptable. In addition, other studies have reported a possibility of other factor solutions, for example, including 6 factors ${ }^{7}$. Using subscores of the different factors can be clinically relevant, as it allows for a more detailed picture than using a total score only. However, researchers should be clear in stating which model is followed in the calculation of the subscores in order to reduce possible errors coming from using different models of RFIPC. In the clinical context, using rank ordering of the individual items might be the best solution as it provides health practitioners with the most specific and precise description of patient's worries, allowing them to tailor the psycho-education and treatment to individual needs. This study is limited by the absence of any prospective measure of RFIPC. This prevented us from accessing whether the Dutch version of the RFIPC is sensitive enough to detect changes in patients' conditions ${ }^{6}$. Second, in this study, we have focused on the Dutchspeaking patients from Belgium who were recruited from a highly specialized reference center, which might receive patients with more severe symptoms limiting the external validity. In addition, our patients were also quite homogenous in terms of medication that they received (i.e., biologic therapy, which is used in less that $50 \%$ of cases). Finally, we have not collected data concerning other disease characteristics. In the case of $C D$, one could differentiate between pure inflammatory disease versus patients with complications such as strictures, fistula and abscesses. Future studies should extend this research to reach a more heterogeneous group of patients with IBD by including patients from the Netherlands, from other reference centers, and following other medical therapies (i.e., 5-aminosalicylates, 
corticosteroids, immunomodulators, small molecules, subcutaneous biological therapies). In addition, in order to assess the sensitivity to change or responsiveness of this questionnaire, future studies should include prospective longitudinal designs.

In conclusion, we have translated the RFIPC into Dutch and validated this version and its factor structure among Dutch-speaking patients with CD and UC in Belgium. The findings were consistent with those in other countries and supported the reliability and validity of the RFIPC. The concerns about the energy level, side effects of medication, having an ostomy bag, having surgery, and uncertain nature of the disease were the most dominant in our sample. The RFIPC can be used in both research and clinical settings to describe and address the worries and concerns of patients with IBD. 


\section{References}

1. Molodecky NA, Soon IS, Rabi DM, et al. Increasing incidence and prevalence of the inflammatory bowel diseases with time, based on systematic review. Gastroenterology. 2012;142:46-54.

2. Farrell D, McCarthy G, Savage E. Self-reported symptom burden in individuals with inflammatory bowel disease. J Crohn's Colitis. 2016;10:315-322.

3. Chen $X L$, Zhong L huan, Wen $Y$, et al. Inflammatory bowel disease-specific healthrelated quality of life instruments: A systematic review of measurement properties. Health Qual Life Outcomes. 2017;15:1-13.

4. Drossman DA, Leserman J, Li Z, Mitchell CM, Zagami EA, Patrick DL. The Rating Form of IBD Patient Concerns: A new measure of health status. Psychosom Med. 1991;53:701-712.

5. Jaghult S. Factor structures of the Swedish Version of the RFIPC: Investigating the validity of measurements of IBD patients' worries and concerns. Gastroenterol Res. 2010;3:191-200.

6. Argyriou K, Roma E, Kapsoritakis A, et al. The Rating Form of IBD Patient Concerns: Translation, validation, and first implementation of the Greek version. Gastroenterol Res Pract. 2017;2017:1-9.

7. Jelsness-Jørgensen L-P, Moum B, Bernklev T. Worries and concerns among inflammatory bowel disease patients followed prospectively over one year. Gastroenterol Res Pract. 2011;2011:1-8.

8. Hjortswang H, Ström M, Almeida RT, Almer S. Evaluation of the RFIPC, a diseasespecific health-related quality of life questionnaire, in Swedish patients with ulcerative colitis. Scand J Gastroenterol. 1997;32:1235-1240.

9. Torres EA, Pérez C, Chinea B, et al. Evaluation of the Rating Form for Inflammatory Bowel Diseases Patients Concerns (RFIPC) Spanish translation in Puerto Ricans with IBD. Am J Gastroenterol. 2000;118:2643.

10. Levenstein S, Li Z, Almer S, et al. Cross-cultural variation in disease-related concerns among patients with inflammatory bowel disease. Am J Gastroenterol. 2001;96:18221830.

11. De Groof EJ, Rossen NGM, Van Rhijn BD, et al. Burden of disease and increasing prevalence of inflammatory bowel disease in a population-based cohort in the 
Netherlands. Eur J Gastroenterol Hepatol. 2016;28:1065-1072.

12. van den Heuvel TRA, Jeuring SFG, Zeegers MP, et al. A 20-year temporal change analysis in incidence, presenting phenotype and mortality, in the Dutch IBDSL cohort-Can diagnostic factors explain the increase in IBD incidence? J Crohn's Colitis. 2017;11:1169-1179.

13. Lennard-Jones JE. Classification of Inflammatory Bowel Disease. Scand J Gastroenterol. 1989;24:2-6.

14. Sperber AD. Guidelines for the translation of Rome Foundation research and diagnostic questionnaires: Adult questionnaires.

15. Lovibond SH, Lovibond PF. Manual for the Depression Anxiety Stress Scales.; 1995.

16. de Beurs E, Van Dyck R, Marquenie LA, Lange A, Blonk RWB. De DASS: Een vragenlijst voor het meten van depressie, angst en stress [The DASS: A questionnaire for the measurement of depression, anxiety, and stress]. Gedragstherapie. 2001;34:35-53.

17. Khanna R, Zou G, D'Haens G, et al. A retrospective analysis: the development of patient reported outcome measures for the assessment of Crohn's disease activity. Aliment Pharmacol Ther. 2015;41:77-86.

18. Jairath V, Khanna R, Zou GY, et al. Development of interim patient-reported outcome measures for the assessment of ulcerative colitis disease activity in clinical trials. Aliment Pharmacol Ther. 2015;42:1200-1210.

19. Benjamini Y, Hochberg Y. Controlling the False Discovery Rate: A practical and powerful approach to multiple testing. J R Stat Soc Ser B. 1995;57:289-300.

20. Hu L, Bentler PM. Cutoff criteria for fit indexes in covariance structure analysis: Conventional criteria versus new alternatives. Struct Equ Model. 1999;6:1-55.

21. Kass RE, Raftery AE. Bayes factors. J Am Stat Assoc. 1995;90:773-795.

22. Terwee CB, Bot SDM, de Boer MR, et al. Quality criteria were proposed for measurement properties of health status questionnaires. J Clin Epidemiol. 2007;60:34-42.

23. Tavakol M, Dennick R. Making sense of Cronbach's alpha. Int J Med Educ. 2011;2:5355. 
Table 1. Inflammatory Bowel Disease worries and concerns - descriptive statistics, numerical ranking, and comparison of disease type (Crohn's Disease vs. Ulcerative Colitis) and disease activity (active disease vs. clinical remission).

\begin{tabular}{|c|c|c|c|c|c|c|}
\hline \multirow[b]{2}{*}{ Item } & \multirow[b]{2}{*}{ Factor } & \multirow[b]{2}{*}{$\begin{array}{l}\text { Total } \\
(n=493-496)^{a}\end{array}$} & \multicolumn{2}{|c|}{ Disease type } & \multicolumn{2}{|c|}{ Disease activity } \\
\hline & & & $\begin{array}{l}\text { CD } \\
(n=332-\end{array}$ & $\begin{array}{l}\text { UC } \\
(n=159-\end{array}$ & $\begin{array}{l}\text { Active } \\
\text { (n=231- }\end{array}$ & $\begin{array}{l}\text { Remission } \\
\text { (n=260- }\end{array}$ \\
\hline & & Mean (SD) & $336)^{a}$ & $160)^{\mathrm{a}}$ & $234)^{a}$ & $262)^{a}$ \\
\hline & & & Mean & Mean & Mean & Mean \\
\hline & & & (rank) & (rank) & (rank) & (rank) \\
\hline Energy level & $\mathrm{F} 1$ & $56.36(28.92)$ & $56.80(1)$ & $55.44(1)$ & $61.01(2)$ & $52.20(1)$ \\
\hline Having an ostomy bag & F3 & $55.98(34.66)$ & $56.37(2)$ & $55.15(2)$ & $61.62(1)$ & $50.92(2)$ \\
\hline Side effects of medication & F1 & $51.97(28.89)$ & $52.33(3)$ & $51.21(3)$ & $55.53(3)$ & $48.79(3)$ \\
\hline $\begin{array}{l}\text { Uncertain nature of the } \\
\text { disease }\end{array}$ & F1 & $49.52(28.87)$ & $50.83(4)$ & $46.78(5)$ & $55.16(4)$ & $44.49(4)$ \\
\hline Having surgery & F3 & $45.52(30.86)$ & $45.05(5)$ & $46.51(6)$ & $50.27(6)$ & $41.27(5)$ \\
\hline Being a burden to others & $\mathrm{F} 1$ & $44.03(30.39)$ & $44.44(6)$ & $43.15(7)$ & $50.31(5)$ & $38.41(7)$ \\
\hline Developing cancer & F3 & $41.65(28.85)$ & $39.15(10)$ & $46.89(4)$ & $44.52(11)$ & $39.10(6)$ \\
\hline $\begin{array}{l}\text { Ability to achieve full } \\
\text { potential }\end{array}$ & F1 & $41.41(26.57)$ & $41.77(7)$ & 40.66 (9) & $45.60(8)$ & $37.69(8)$ \\
\hline Feeling out of control & $\mathrm{F} 1$ & $41.05(28.67)$ & $41.12(8)$ & $40.92(8)$ & $48.15(7)$ & $34.71(10)$ \\
\hline Feelings about my body & $\mathrm{F} 1$ & $39.80(27.96)$ & $39.63(9)$ & $40.18(10)$ & $45.49(9)$ & $34.72(9)$ \\
\hline Loss of bowel control & $\mathrm{F} 1$ & $36.59(30.37)$ & $36.58(12)$ & $36.63(13)$ & $45.29(10)$ & $28.83(16)$ \\
\hline Producing unpleasant smell & $\mathrm{F} 4$ & $36.53(31.41)$ & $35.83(13)$ & $37.99(12)$ & $43.35(13)$ & $30.44(13)$ \\
\hline Pain or suffering & $\mathrm{F} 1$ & $36.39(25.90)$ & $37.30(11)$ & $34.47(15)$ & $43.44(12)$ & $30.09(15)$ \\
\hline Dying early & F3 & $35.41(28.88)$ & $33.48(17)$ & $39.47(11)$ & $37.99(18)$ & $33.11(11)$ \\
\hline Loss of sexual drive & F2 & $34.43(29.67)$ & $34.10(15)$ & $35.13(14)$ & $39.20(15)$ & $30.15(14)$ \\
\hline Intimacy & F2 & $33.62(27.95)$ & $33.69(16)$ & $33.47(16)$ & $39.40(14)$ & $28.43(17)$ \\
\hline Attractiveness & $\mathrm{F} 1$ & $33.03(26.37)$ & $34.23(14)$ & $30.50(21)$ & $38.72(16)$ & $27.94(18)$ \\
\hline Ability to perform sexually & F2 & $32.39(27.55)$ & $32.81(18)$ & $31.52(18)$ & $37.43(19)$ & $27.91(19)$ \\
\hline $\begin{array}{l}\text { Having access to quality } \\
\text { medical care }\end{array}$ & F1 & $31.81(29.19)$ & $32.32(19)$ & $30.75(19)$ & 38.09 (17) & $26.21(20)$ \\
\hline $\begin{array}{l}\text { Passing the disease on to } \\
\text { others }^{b}\end{array}$ & & 31.22 (30.99) & $30.91(20)$ & $31.86(17)$ & $31.84(22)$ & $30.66(12)$ \\
\hline Feeling alone & $\mathrm{F} 1$ & $29.24(26.20)$ & $28.63(22)$ & $30.51(20)$ & $34.08(20)$ & $24.91(21)$ \\
\hline Being treated as different ${ }^{b}$ & & $27.88(26.45)$ & $27.88(23)$ & $27.87(22)$ & $32.91(21)$ & $23.39(22)$ \\
\hline
\end{tabular}




$\begin{array}{lllllll}\text { Feeling dirty or smelly } & \text { F4 } & 25.07(26.16) & 24.15(24) & 27.00(23) & \mathbf{3 0 . 9 5 ( 2 3 )} & \mathbf{1 9 . 8 5 ( 2 4 )} \\ \text { Financial difficulties } & \text { F1 } & 24.48(23.91) & 29.20(21) & 22.97(24) & \mathbf{2 8 . 9 4}(\mathbf{2 4}) & \mathbf{2 0 . 5 0 ( 2 3 )} \\ \text { Ability to have children }{ }^{b} & & 21.29(26.72) & 22.90(25) & 17.94(25) & \mathbf{2 3 . 8 9}(\mathbf{2 5}) & \mathbf{1 8 . 9 9 ( 2 5 )} \\ \text { Total score; mean (SD) } & & 37.48(18.60) & 37.52 & 37.41 & \mathbf{4 2 . 5 4} & \mathbf{3 2 . 9 7} \\ & & & (18.00) & (19.86) & \mathbf{( 1 8 . 7 5 )} & \text { (17.29) }\end{array}$

a Differences in sample size due to limited amount of missing data.

${ }^{b}$ Following the model of Drossman ${ }^{4}$, those items are only included in the total score.

SD = Standard Deviation; CD = Crohn's Disease; UC = Ulcerative Colitis; F1 = Impact of disease; F2 = Sexual intimacy; F3 = Complications; F4 = Body Stigma.

Differences between values displayed in bold are significant at $p<.05$. P-values were adjusted for multiple (i.e., 25) comparisons using the Benjamini-Hochberg procedure. 
Table 2. Goodness-of-fit statistics for the measurement models of the Rating Form of IBD Patient Concerns for the full patient sample $(n=496)$.

\begin{tabular}{|c|c|c|c|c|c|c|c|}
\hline Model & Model description & $\chi^{2}$ & $d f$ & $\mathrm{CFI}$ & RMSEA & $\begin{array}{l}90 \% \mathrm{Cl} \\
\text { RMSEA }\end{array}$ & $\mathrm{BIC}$ \\
\hline Model 1 & 4 factors $^{4}$ & $1017.25^{* * *}$ & 203 & .87 & .09 & $.08-.10$ & 98832 \\
\hline Model 2 & $\begin{array}{l}4 \text { factors, CE items } \\
16 \& 17^{6}\end{array}$ & $957.14 * * *$ & 202 & .88 & .09 & $.08-.09$ & 98779 \\
\hline Model 3 & $\begin{array}{l}4 \text { factors, CE items } 5 \\
\& 6,16 \& 17^{5}\end{array}$ & $838.76 * * *$ & 201 & .90 & .08 & $.07-.09$ & 98666 \\
\hline Model 4 & 6 factors $^{7}$ & $844.42 * * *$ & 194 & .89 & .08 & $.08-.09$ & 99160 \\
\hline
\end{tabular}

$* * * p<.001$. 
Table 3. Descriptive statistics (number of items, mean, standard deviation (SD), range, and the percentage of patients reaching the lowest (score $\leq 5$ ) and highest (score $\geq 95$ ) possible scores) of the total score and four subscales of the Rating Form of IBD Patient Concerns (RFIPC) in the total sample $(n=492-496)$, and correlations with Depression Anxiety Stress Scales (DASS-21).

\begin{tabular}{|c|c|c|c|c|c|c|c|c|c|}
\hline \multirow[b]{2}{*}{ RFIPC } & \multirow[b]{2}{*}{$\begin{array}{l}\text { Number } \\
\text { of items }\end{array}$} & \multirow[b]{2}{*}{ Mean (SD) } & \multirow[b]{2}{*}{ Range } & \multirow[b]{2}{*}{$\begin{array}{l}\text { Floor effect } \\
\text { (Score } \leq 5)\end{array}$} & \multirow[b]{2}{*}{$\begin{array}{l}\text { Ceiling effect } \\
\text { (Score } \geq 95 \text { ) }\end{array}$} & \multirow[b]{2}{*}{$\begin{array}{l}\text { Cronbach's } \\
\text { alpha }\end{array}$} & \multicolumn{3}{|c|}{ Correlations with DASS-21 } \\
\hline & & & & & & & Depression & Anxiety & Stress \\
\hline Total score & $25^{\mathrm{a}}$ & $37.48(18.60)$ & $0-81$ & $3 \%$ & $0 \%$ & .94 & $.49 * * *$ & $.49 * * *$ & $.46 * * *$ \\
\hline Impact of disease & 13 & $39.67(19.26)$ & $0-87$ & $2 \%$ & $0 \%$ & .91 & $.51 * * *$ & $.51 * * *$ & $.48^{* * *}$ \\
\hline Sexual intimacy & 3 & $33.51(25.81)$ & $0-99$ & $16 \%$ & $1 \%$ & .89 & $.42^{* * *}$ & $.41 * * *$ & $.37^{* * *}$ \\
\hline Complications & 4 & $44.64(24.39)$ & $0-100$ & $5 \%$ & $1 \%$ & .80 & $.31^{* * *}$ & $.34 * * *$ & $.31 * * *$ \\
\hline Body stigma & 2 & $30.82(26.24)$ & $0-100$ & $20 \%$ & $1 \%$ & .79 & $.36^{* * *}$ & $.31 * * *$ & $.30 * * *$ \\
\hline
\end{tabular}

a Following the model of Drossman 4 , items "Passing disease to others", "Being treated as different", and "Ability to have children" are only included in the total score.

$* * * p<.001$. 
Supplementary Table 1. Inflammatory Bowel Disease worries and concerns - descriptive statistics and comparison of disease activity (active disease vs. clinical remission) within the disease type (Crohn's Disease vs. Ulcerative Colitis).

\begin{tabular}{|c|c|c|c|c|}
\hline \multirow{3}{*}{ Item } & \multicolumn{2}{|c|}{ Crohn's Disease } & \multicolumn{2}{|c|}{ Ulcerative Colitis } \\
\hline & $\begin{array}{l}\text { Active disease } \\
(\mathrm{n}=180-183)^{\mathrm{a}}\end{array}$ & $\begin{array}{l}\text { Remission } \\
(n=152-153)^{a}\end{array}$ & $\begin{array}{l}\text { Active disease } \\
(n=51)\end{array}$ & $\begin{array}{l}\text { Remission } \\
(n=108-109)^{a}\end{array}$ \\
\hline & Mean (SD) & Mean (SD) & Mean (SD) & Mean (SD) \\
\hline Financial difficulties & $29.88(25.65)$ & $19.60(20.96)$ & $25.56(24.02)$ & $21.76(23.11)$ \\
\hline Pain or suffering & $43.76(26.22)$ & $29.58(22.87)$ & $42.27(27.95)$ & $30.82(24.77)$ \\
\hline Ability to achieve full potential & $46.01(26.63)$ & $36.74(24.49)$ & $44.16(29.25)$ & $39.02(26.94)$ \\
\hline Loss of bowel control & $44.54(29.96)$ & $27.05(27.13)$ & 47.97 (32.09) & $31.32(29.63)$ \\
\hline Developing cancer & $43.22(29.91)$ & $34.30(26.55)$ & $49.15(26.56)$ & $45.83(29.38)$ \\
\hline Dying early & $37.55(30.04)$ & $28.62(25.92)$ & $39.60(29.41)$ & $39.40(29.30)$ \\
\hline Being a burden to others & $50.47(29.32)$ & $37.22(28.04)$ & $49.72(33.56)$ & $40.08(31.47)$ \\
\hline Attractiveness & $39.90(28.81)$ & $27.46(22.19)$ & $34.51(28.77)$ & $28.62(23.81)$ \\
\hline Feeling alone & $33.30(27.46)$ & 23.05 (22.09) & $36.87(31.54)$ & $27.53(24.80)$ \\
\hline Feeling out of control & $47.76(28.34)$ & $33.17(25.29)$ & $49.54(32.24)$ & $36.88(28.60)$ \\
\hline Feeling dirty or smelly & $30.81(28.00)$ & $16.24(18.28)$ & $31.44(30.50)$ & $24.92(27.00)$ \\
\hline Ability to perform sexually & $38.14(29.09)$ & $26.46(24.56)$ & $34.88(28.46)$ & $29.94(26.71)$ \\
\hline Ability to have children & $25.65(30.10)$ & $19.63(24.78)$ & $17.65(23.04)$ & $18.08(24.24)$ \\
\hline Passing the disease on to others & $32.17(31.61)$ & $29.41(30.95)$ & $30.64(30.77)$ & $32.43(30.39)$ \\
\hline Being treated as different & $32.98(27.60)$ & $21.83(23.31)$ & $32.66(29.09)$ & $25.60(25.60)$ \\
\hline Having surgery & $49.51(30.62)$ & $39.74(30.01)$ & $52.98(34.72)$ & $43.45(29.22)$ \\
\hline Having an ostomy bag & $61.34(34.34)$ & $50.41(33.24)$ & $62.63(36.20)$ & $51.62(34.98)$ \\
\hline Producing unpleasant smell & $42.66(32.09)$ & $27.71(27.24)$ & $45.83(33.47)$ & $34.29(31.68)$ \\
\hline Energy level & $62.65(27.06)$ & $49.80(29.76)$ & $55.14(29.09)$ & $55.57(28.84)$ \\
\hline Feelings about my body & $46.19(28.85)$ & $31.82(24.54)$ & $43.00(30.48)$ & $38.84(27.16)$ \\
\hline Intimacy & $40.13(29.73)$ & $25.98(23.70)$ & $36.76(29.90)$ & $31.91(26.88)$ \\
\hline Loss of sexual drive & $39.85(31.76)$ & $27.22(26.03)$ & $36.89(29.76)$ & $34.29(29.09)$ \\
\hline Having access to quality medical care & $37.91(31.34)$ & $25.63(25.65)$ & $38.74(30.38)$ & $27.01(27.06)$ \\
\hline Uncertain nature of the disease & $55.89(27.53)$ & $44.78(28.75)$ & $52.54(29.35)$ & $44.08(29.08)$ \\
\hline Side effects of medication & $57.14(28.72)$ & $46.57(28.52)$ & $49.76(28.92)$ & $51.89(28.53)$ \\
\hline Total score & $42.79(17.96)$ & 31.21 (15.95) & $41.64(21.52)$ & $35.43(18.81)$ \\
\hline
\end{tabular}

\footnotetext{
${ }^{a}$ Differences in sample size due to limited amount of missing data.
}

$\mathrm{SD}=$ Standard Deviation; Differences between values displayed in bold are significant at $p<.05$. P-values were adjusted for multiple (i.e., 25) comparisons using the Benjamini-Hochberg procedure. 
Supplementary Table 2. The descriptive statistics of the total score and four subscales of the Rating Form of IBD Patient Concerns (RFIPC) for gender, relationship status, education, and age.

\begin{tabular}{|c|c|c|c|c|c|c|c|}
\hline \multirow[b]{2}{*}{ Variable } & \multirow[b]{2}{*}{ Group } & \multirow[b]{2}{*}{$\begin{array}{l}\text { Sample } \\
\text { size }(n)\end{array}$} & \multicolumn{5}{|c|}{ RFIPC } \\
\hline & & & Total & F1 & F2 & F3 & F4 \\
\hline \multirow{3}{*}{ Gender } & & & $\begin{array}{l}\text { Mean } \\
\text { (SD) }\end{array}$ & $\begin{array}{l}\text { Mean } \\
\text { (SD) }\end{array}$ & $\begin{array}{l}\text { Mean } \\
\text { (SD) }\end{array}$ & $\begin{array}{l}\text { Mean } \\
\text { (SD) }\end{array}$ & $\begin{array}{l}\text { Mean } \\
\text { (SD) }\end{array}$ \\
\hline & Men & 240 & $\begin{array}{l}32.01 \\
(17.66)\end{array}$ & $\begin{array}{l}33.78 \\
(18.15)\end{array}$ & $\begin{array}{l}27.20 \\
(23.68)\end{array}$ & $\begin{array}{l}40.11 \\
(24.25)\end{array}$ & $\begin{array}{l}24.52 \\
(22.95)\end{array}$ \\
\hline & Women & 256 & $\begin{array}{l}42.61 \\
(18.02)\end{array}$ & $\begin{array}{l}45.19 \\
(18.65)\end{array}$ & $\begin{array}{l}39.43 \\
(26.35)\end{array}$ & $\begin{array}{l}48.89 \\
(23.79)\end{array}$ & $\begin{array}{l}36.74 \\
(27.76)\end{array}$ \\
\hline \multirow{2}{*}{ Relationship } & No & 102 & $\begin{array}{l}36.52 \\
(17.48)\end{array}$ & $\begin{array}{l}39.17 \\
(18.36)\end{array}$ & $\begin{array}{l}28.06 \\
(22.28)\end{array}$ & $\begin{array}{l}44.57 \\
(24.60)\end{array}$ & $\begin{array}{l}27.09 \\
(24.35)\end{array}$ \\
\hline & Yes & 394 & $\begin{array}{l}37.73 \\
(18.89)\end{array}$ & $\begin{array}{l}39.80 \\
(19.50)\end{array}$ & $\begin{array}{l}34.93 \\
(26.49)\end{array}$ & $\begin{array}{l}44.66 \\
(24.36)\end{array}$ & $\begin{array}{l}31.78 \\
(26.65)\end{array}$ \\
\hline \multirow{2}{*}{ Education } & $\begin{array}{l}\text { High school } \\
\text { or lower }\end{array}$ & 236 & $\begin{array}{l}38.79 \\
(19.05)\end{array}$ & $\begin{array}{l}40.79 \\
(19.59)\end{array}$ & $\begin{array}{l}34.76 \\
(26.24)\end{array}$ & $\begin{array}{l}46.80 \\
(24.72)\end{array}$ & $\begin{array}{l}33.77 \\
(27.70)\end{array}$ \\
\hline & University & 259 & $\begin{array}{l}36.32 \\
(18.17)\end{array}$ & $\begin{array}{l}38.67 \\
(18.96)\end{array}$ & $\begin{array}{l}32.47 \\
(25.41)\end{array}$ & $\begin{array}{l}42.74 \\
(23.99)\end{array}$ & $\begin{array}{l}28.10 \\
(24.62)\end{array}$ \\
\hline \multirow[b]{2}{*}{ Age } & $\begin{array}{l}\leq 40 \text { years } \\
\text { old }\end{array}$ & 252 & $\begin{array}{l}38.48 \\
(18.38)\end{array}$ & $\begin{array}{l}41.16 \\
(19.12)\end{array}$ & $\begin{array}{l}32.63 \\
(26.47)\end{array}$ & $\begin{array}{l}43.12 \\
(23.49)\end{array}$ & $\begin{array}{l}28.76 \\
(24.46)\end{array}$ \\
\hline & $\begin{array}{l}>40 \text { years } \\
\text { old }\end{array}$ & 242 & $\begin{array}{l}36.45 \\
(18.86)\end{array}$ & $\begin{array}{l}38.07 \\
(19.28)\end{array}$ & $\begin{array}{l}34.56 \\
(25.18) \\
\end{array}$ & $\begin{array}{l}46.36 \\
(25.28)\end{array}$ & $\begin{array}{l}32.71 \\
(27.71) \\
\end{array}$ \\
\hline \multicolumn{8}{|c|}{ SD = Standard Deviation; F1 = Impact of disease; F2 = Sexual intimacy; F3 = Complications; F4 = } \\
\hline
\end{tabular}

